\title{
Book Review for "Credit Default Swap Markets in the Global Economy" by Go Tamakoshi and Shigeyuki Hamori. Routledge: Oxford, UK, 2018; ISBN: 9781138244726
}

\author{
Haifeng Xu \\ Department of Statistics, School of Economics, Xiamen University, Xiamen 360000, China; \\ xhf1984@hotmail.co.jp or xhf1984@gmail.com
}

Received: 22 October 2018; Accepted: 24 October 2018; Published: 25 October 2018

Credit default swaps (CDS) came into existence in 1994 when they were invented by JP Morgan, then it became popular in the early 2000s, and by 2007, the outstanding credit default swaps balance reached $\$ 62$ trillion. During the financial crisis of 2008, the balance of CDS was hit hard, and it dropped to $\$ 25.5$ trillion in 2012 . The role of credit default swaps in the financial crisis has attracted increased attention from regulators, market participants, and academics.

This book focuses on the CDS market and provides many important results using various advanced econometric methodologies. The book provides a comprehensive overview of global CDS markets and focuses on three main segments of CDS markets: Sovereign CDS markets, Sector-level CDS markets, and Firm-level CDS markets.

The main contents of the book are as follows. In the first part, around sovereign CDS markets, the book shows: (1) The causality between the spread of the sovereign CDS index and the banking sector CDS index; (2) The determinants of sovereign CDS spreads; and (3) The spillover effects across sovereign CDS rates. In the second part, it focuses on: (1) The causal relationships amongst financial sector CDS indices at the sector level; (2) Financial crises and their effects, by focusing on the CDS indexes of three financial industries; (3) The relationships between insurance sector CDS indices across countries; and (4) The dynamic relationship between bank sector CDS indices for several countries. In the final part, they examine: (1) The co-movement of bank CDS spreads of Eurozone banks; (2) The conditional dependence structure of the three main CDS indices; and (3) The dynamic interdependency of CDS indices in different cycles.

I strongly recommend this book to policymakers, investors, researchers, and graduate students, based on the following reasons. First, it summarizes a large number of literature and provides a helpful reference for researchers aiming to build a solid knowledge base about CDS markets and the financial crisis. Specifically, the introduction of every section describes the background and research progress, wherein academics will benefit from these parts.

Second, the book provides several empirical researches that apply advanced econometric methodologies. Empirical methodologies are explained in every section before application. Graduate students can use it as a textbook or supplementary reading material when studying time series analysis. The methodology in this book, which includes, but is not limited to the cross-correlation function (CCF) approach, auto regressive distributed lag (ARDL) bounds test approach, dynamic conditional correlation (DCC) GARCH model, copula-GARCH approach, dynamic equi-correlation (DECO) model, and the continuous wavelet transform.

Third, the results of this book are interesting and impressive. They are useful for market participants and policymakers who design and implement regulatory frameworks to ensure properly functioning financial markets. Furthermore, the book provides implications and discussions of the 
results. What is the economics behind the results? It is important to understand CDS and the financial crises at work behind our own actions.

Finally, the contents of this book cover well-studied sovereign CDS markets, as well as sector-level and firm-level CDS indices, suggesting it could make a major contribution.

Although CDS markets have experienced a significant rise and fall, CDS have many benefits if used appropriately. This book shows the benefits and provides guidance in dealing with existence problems.

Funding: This research received no external funding.

Conflicts of Interest: The author declares no conflict of interest. 